\title{
High School Teachers' Perception on Content and Timing of Sex Education in Ife Central Local Government, Osun, Nigeria
}

\author{
Oni Oluwabunmi Bola ${ }^{1}$, Ayandiran Olufemi ${ }^{1}$, Olajide Joshua Seun ${ }^{2}$ \\ ${ }^{1}$ Department of Nursing Science, Obafemi Awolowo University, Ile-Ife, Nigeria \\ ${ }^{2}$ Centre for Distance Learning, Obafemi Awolowo University, Ile-Ife, Nigeria
}

Email address:

bettybola90@gmail.com (O. O. Bola)

\section{To cite this article:}

Oni Oluwabunmi Bola, Ayandiran Olufemi, Olajide Joshua Seun. High School Teachers' Perception on Content and Timing of Sex Education in Ife Central Local Government, Osun, Nigeria. Teacher Education and Curriculum Studies. Vol. 2, No. 6, 2017, pp. 105-109. doi: $10.11648 /$ j.tecs. 20170206.15

Received: February 28, 2017; Accepted: May 31, 2017; Published: January 12, 2018

\begin{abstract}
Sex education is out of bounds in a typical African society due to cultural values and belief systems. So, sex education is assumed to support promiscuity among adolescents. Premised on this, teachers equally have lopsided views of responsibility. This greatly has hampered the success of inculcation of sex education in high school curriculum and the teaching of the subject. This study aimed to assess the perception of high school teachers towards the contents and timing of sex education in secondary schools in Ile-Ife, South-West Nigeria. 200 high school teachers were randomly selected and served questionnaire that has been pretested and standardized for data collection. Data collected was analyzed using descriptive statistics. Teachers' responses showed positive attitude towards sex education and its inclusion into secondary school curriculum. Higher numbers of the respondents were of the opinion that it is best suited for Secondary schools. However, there were discrepancies as regard the appropriate age at which students should be taught sex education. Also, there were variants on the contents of sex education curriculum. One-third of the teachers indicated that 16 to 18 years were appropriate for sex education. Foremost among the factors identified affecting introduction of sex education into school curriculum were culture, religion, mass media and peer influence. The study concluded that appropriate age, timing and class are major factors to be considered before the introduction of sex education into secondary school curriculum.
\end{abstract}

Keywords: Sexuality, Education, Curriculum, Perception, Content

\section{Introduction}

Adolescents' sexual and reproductive health concerns have over the years been a topical issue. However, the societal and cultural ideologies about sexuality and reproductive health have been, and are possibly still being, ignored. Majority of adolescents remained uninformed about sex and sexuality and hence vulnerable to sexual escapades with its negative consequences. Absence of sexual and reproductive health education makes adolescents vulnerable to daunting reproductive and sexual health problems [1].

In Nigeria, discussion on bodily maturation, sexuality, birth control and parenting with adolescents in the family is usually a contentious issue. This has been attributed largely to cultural views, values, beliefs, norms and environment. However, there is no justifiable excuse for denying the teeming, adventureprone adolescents of comprehensive sexual education. In consonance with this, the United Nations submits that the enjoyment of the right to sexual education plays a crucial preventive role and may be a question of life or death [2]. Similarly, sexual education was identified as a human right, since it is essential for development and human well-being. Additionally, sexual health is one of five core aspects of the global reproductive health strategy approved by the World Health Assembly [3]. WHO noted that sexuality is influenced by the interaction of biological, psychological, social, economic, political, ethical, legal, historical, religious and spiritual factors [4]. Similarly, it was argued that sexuality education encompasses education about all aspects of sexual orientation and pleasure including information about family 
planning, body image, values, decision making, communication and dating. It also includes knowledge of sexually transmitted infections and birth control method [5].

While parents are the primary contact for socialization, schools play important role as secondary socializing agent of adolescents in schools. Teachers, therefore, occupy a pivotal role in the lives of students. First, because they develop the academic potential of young people and two, the influence they have in behavioral development and charting the course life of adolescents. It is not surprising then that, several researchers have reported the roles of teachers in school-based reproductive health programme as critical to addressing reproductive health challenges of inschool adolescents [6]. As in all areas of education, sexual education must be adapted to different age groups and cultures. In addition, teaching strategies must be differentiated and flexible to meet the differing needs of female and male students. Comprehensive sexual education is extremely important especially for groups at greater risk, women and girls exposed to gender-based violence or persons in difficult financial circumstances.

Sexual education has been described as planned process of education that fosters the acquisition of factual information of positive attitudes, beliefs and values and development of skills to cope with human sexuality. Sexuality education is a lifelong process of acquiring information about identity and intimacy, reproductive health, interpersonal relationships, body image and gender roles [7]. Sexuality education addresses the biological, socio-cultural, psychological, and spiritual dimensions of human sexuality [8]. In order of appropriateness, sexual education must be age-appropriate, fact-based and medically accurate. Also, it must be culturally acceptable among parents, family, peers, school teachers and community [9]. Despite the acclaimed dividends of sex education, there has been an age-long controversy over appropriateness of inculcation of sex education in Nigerian secondary schools curriculum. Past research work showed that many of the sexual health problems among the adolescents can only be addressed through inclusion of sex education that is constructive and result oriented, into secondary school curriculum [10].

In Nigeria, there has been no substantial report on the perception of high school teachers on the content and timing of sex education. Assumption has it that, implementations of policies, instructions or curricula are easier when well informed stakeholders are at the hem of decision making. However, because of strong cultural and religious belief systems of parents and/or teachers, there is subtle reservation on the discussion of human sexuality in schools among adolescents. This study was designed to assess high school teachers' perception on the content and timing of sex education with a view to reducing risks of harmful sexual behaviours among school adolescents and to improve their reproductive health.

\section{Methodology}

A cross sectional study was adopted to assess the factors affecting the teaching of sex education and sexuality in secondary school. Adopting simple random sampling technique, four government and four private high schools selected. Ethical clearance was granted by the Institute of Public Health Research Ethics Committee, Obafemi Awolowo University, Ile-Ife, Nigeria. Purposive random sampling technique was used in the selection of teachers. Informed consent was sought appropriately. A well-structured, selfadministered, pre-tested, close ended questionnaire was used as instrument for data collection. The reliability of the questionnaire was established by split half reliability technique. Completed questionnaire was subjected to homogeneity test to determine its reliability. Apart from socio-demographic data, other sections of the questionnaire were test for internal consistency using Cronbach's Alpha score. The data collected was subjected to descriptive statistics using Statistical Package for Social Science (SPSS) version 21.

\section{Results}

The ages of the respondents ranged between 20 and 60 years. Teachers within the age group 31-35 had the highest percentage (18.7\%) while respondents of between 20 and 25 years had the lowest percentage $(6.6 \%) .84(42.4 \%)$ of the respondents were male while $112(56.6 \%)$ were female. The teachers who were holder of Bachelor's degree accounted for 71 (35.9\%) while 20 (10.1\%) had obtained Master of Science degree as highest educational qualification. The result of the findings showed that $91(46.0 \%)$ of the respondents have spent 1 to 10 years in active service while $17(8.6 \%)$ have spent $31-35$ years in service. Government school teachers were $123(62.1 \%)$ while private schools had 75 (37.9\%) teachers interviewed. Majority of the teachers $(99.4 \%)$ were positive about inclusion of sex education into the school curriculum (Table 1).

Table 1. Socio-demographic Characteristics of High School Teachers.

\begin{tabular}{lll}
\hline Variables & Frequency & Percentage \\
\hline Age of teachers in years & 3 & \\
No response & 13 & 1.5 \\
$20-25$ & 26 & 6.6 \\
$26-30$ & 37 & 13.1 \\
$31-35$ & 35 & 18.7 \\
$36-40$ & 22 & 17.7 \\
$41-45$ & 29 & 11.1 \\
$46-50$ & 33 & 14.6 \\
$50-60$ & 198 & 16.7 \\
TOTAL & & 100.0 \\
SEX & 2 & \\
No response & 84 & 1.0 \\
Male & 112 & 42.4 \\
Female & 198 & 56.6 \\
TOTAL & & 100.0 \\
RELIGION & 1 & \\
No response & 156 & 0.5 \\
Christianity & 38 & 78.8 \\
Islam & 2 & 19.2 \\
Traditional & 1 & 1.0 \\
Others & 198 & 0.5 \\
TOTAL & & 100.0 \\
EDUCATIONAL LEVEL & & \\
\hline
\end{tabular}




\begin{tabular}{lll}
\hline Variables & Frequency & Percentage \\
\hline No response & 4 & 2.0 \\
NCE & 34 & 17.2 \\
B. Edu & 69 & 34.8 \\
B. Sc & 71 & 35.9 \\
M. Sc & 20 & 10.1 \\
TOTAL & 198 & 100.0 \\
ETHNICITY & & \\
No response & 4 & 2.0 \\
Yoruba & 174 & 87.9 \\
Igbo & 17 & 8.6 \\
Hausa & 1 & 0.5 \\
Others & 2 & 1.0 \\
TOTAL & 198 & 100.0 \\
MARITAL & & \\
No response & 2 & 1.0 \\
Single & 54 & 27.3 \\
Married & 135 & 68.2 \\
Divorced & 3 & 1.5 \\
Widow & 4 & 2.0 \\
TOTAL & 198 & 100.0 \\
CATEGORY OF SCHOOL & & \\
Public & 123 & 62.1 \\
Private & 75 & 37.9 \\
TOTAL & 198 & 100.0 \\
\hline
\end{tabular}

The content of sex education curriculum was viewed differently by the respondents as $193(97.5 \%)$ of the respondents agreed that physical and social changes associated with puberty should be included in sex education curriculum, $4(2.0 \%)$ disagreed with such inclusion. 178 $(89.9 \%)$ agreed that sexually transmitted diseases should be included into the curriculum as $19(9.6 \%)$ of the respondents disagreed with its inclusion. $148(73.7 \%)$ agreed that family planning and birth control should be included as $52(26.3 \%)$ disagreed with inclusion of family planning and birth control. $153(77.2 \%)$ were of the opinion that developing and managing intimate relationship should be included in sex education curriculum but $55(22.8 \%)$ declined its inclusion. $164(82.8 \%)$ agreed that abortion and complications of unsafe abortion should be part of the curriculum but 33 (16.7\%) opposed its inclusion into the secondary school curriculum. $114(57.6 \%)$ wanted homosexuality to be part of sex education curriculum whereas 72 (36.4\%) disagreed with its inclusion (Table 2).

Table 2. Teachers Opinions on Contents of Sex Education.

\begin{tabular}{|c|c|c|c|c|c|c|}
\hline \multirow{2}{*}{ Items } & \multicolumn{2}{|c|}{ AGREE } & \multicolumn{2}{|c|}{ DISAGREE } & \multicolumn{2}{|c|}{ NO RESPONSE } \\
\hline & Freq & $\%$ & Freq & $\%$ & Freq & $\%$ \\
\hline Physical and social changes associated with puberty. & 193 & $97.5 \%$ & 4 & $2.0 \%$ & 1 & $0.5 \%$ \\
\hline Sexually transmitted diseases. & 178 & $89.9 \%$ & 19 & $9.6 \%$ & 1 & $0.5 \%$ \\
\hline Abstinence and its relationship with healthy living. & 174 & $87.8 \%$ & 22 & $11.1 \%$ & 2 & $1.0 \%$ \\
\hline The reproductive systems of both male and female and their functions. & 186 & $94.0 \%$ & 12 & $6.0 \%$ & 0 & $0.0 \%$ \\
\hline Reproduction and sexual relationships. & 169 & $85.4 \%$ & 26 & $13.1 \%$ & 5 & $1.5 \%$ \\
\hline Family planning/ birth control. & 148 & $73.7 \%$ & 52 & $26.3 \%$ & 0 & $0.0 \%$ \\
\hline Positive values about self-image. & 182 & $91.9 \%$ & 16 & $8.1 \%$ & 0 & $0.0 \%$ \\
\hline Discipline and self-control particularly as related to sexual matters. & 183 & $92.4 \%$ & 15 & $7.6 \%$ & 0 & $0.0 \%$ \\
\hline Learning positive un-exploitative gender roles e.g. leadership, nurturing etc. & 180 & $91.0 \%$ & 18 & $9.0 \%$ & 0 & $0.0 \%$ \\
\hline Developing and managing intimate relationship. & 153 & $77.2 \%$ & 55 & $22.8 \%$ & 0 & $0.0 \%$ \\
\hline Premarital sex and teenage pregnancies. & 171 & $86.4 \%$ & 25 & $12.7 \%$ & 2 & $1.0 \%$ \\
\hline Abortion and complications of unsafe abortion. & 164 & $82.8 \%$ & 33 & $16.7 \%$ & 1 & $0.5 \%$ \\
\hline Rape and its effects on the physical, social and psychological wellbeing of people. & 181 & $91.4 \%$ & 17 & $8.6 \%$ & 0 & $0.0 \%$ \\
\hline The menace of sexual abuse. & 181 & $91.4 \%$ & 16 & $8.1 \%$ & 1 & $0.5 \%$ \\
\hline Homosexuality. & 114 & $57.6 \%$ & 72 & $36.4 \%$ & 12 & $6.0 \%$ \\
\hline
\end{tabular}

Table 3 shows the opinions of high school teachers about the appropriate timing, age and school class at which sex education should be taught. $13(6.6 \%)$ respondents reportedly agreed that sex education should begin between Primary three to six, although $60(30.3 \%)$ opined that it should start in tertiary class. $66(33.3 \%)$ of the teachers agreed that sex education should be introduced between ages 13-15 but opposed by $4(2.1 \%)$ who indicated that it should be introduced from age 21 and above. $132(66.7 \%)$ of the teachers agreed that sex education should begin in secondary schools while $7(3.5 \%)$ said it should start in the university.

Table 3. Teachers' Opinion about Appropriate Timing, Age and Class for Sex Education.

\begin{tabular}{lll}
\hline Variables & Frequency & Percentage \\
\hline Level of education & & \\
No response & 8 & 4.0 \\
Primary school & 43 & 21.7 \\
Secondary school & 132 & 66.7 \\
\hline
\end{tabular}

\begin{tabular}{lll}
\hline Variables & Frequency & Percentage \\
\hline College & 8 & 4.0 \\
University & 7 & 3.5 \\
TOTAL & 198 & 100.0 \\
TIMING & & \\
Primary 3-6 & 13 & 6.6 \\
Jss 1-3 & 43 & 21.7 \\
SS 1-3 & 82 & 41.4 \\
Tertiary class & 60 & 30.3 \\
TOTAL & 198 & 100.0 \\
AGE & & \\
$9-12$ & 7 & 3.5 \\
13-15 & 54 & 27.3 \\
16-18 & 66 & 33.3 \\
19-21 & 49 & 24.7 \\
21 and above & 18 & 9.1 \\
TOTAL & 198 & 100.0 \\
\hline
\end{tabular}

Various factors were reportedly said to influence inclusion of sex education into school curriculum, 141 (71.2\%) of the respondents recognized religion as an influencing factor for 
including sex education into school curriculum, 150 (75.8\%) said culture is an influencing factor, $100(50.5 \%)$ identified mass media, films and teenage pregnancy as influencing factors. Social media was pointed by $78(39.4 \%)$ respondents as influencing factor. Also, 87 (43.9\%) said increase in rate of acquiring STIs is an influencing factor. 94 (47.5\%), 52 $(26.3 \%)$ and $125(63.1 \%)$ identified rape/sexual harassment, peer influence and tutors respectively as influencing factors (Table 4).

Table 4. Teachers Opinion on Factors Influencing Inclusion of Sex Education into School Curriculum.

\begin{tabular}{|c|c|c|c|c|}
\hline \multirow{2}{*}{ VARIABLES } & \multicolumn{2}{|l|}{ WRITTEN } & \multicolumn{2}{|l|}{ NOT WRITTEN } \\
\hline & FREQUENCY & PERCENTAGE & FREQUENCY & PERCENTAGE \\
\hline RELIGION & 141 & $71.2 \%$ & 57 & $28.8 \%$ \\
\hline CULTURE & 150 & $75.8 \%$ & 48 & $24.2 \%$ \\
\hline MASS MEDIA\& FILMS & 100 & $50.5 \%$ & 98 & $49.5 \%$ \\
\hline SOCIAL MEDIA & 78 & $39.4 \%$ & 120 & $60.6 \%$ \\
\hline TEENAGE PREGNANY & 100 & $50.5 \%$ & 98 & $49.5 \%$ \\
\hline STI's & 87 & $43.9 \%$ & 111 & $56.1 \%$ \\
\hline PEER INFLUENCE & 52 & $26.3 \%$ & 146 & $73.7 \%$ \\
\hline TUTORS & 125 & $63.1 \%$ & 73 & $38.9 \%$ \\
\hline
\end{tabular}

\section{Discussion}

Majority of respondents have favourable attitude to the inclusion of sex education into school curriculum. This was in coherence with various works including works done in various continents [11] [12]. More female participants were recorded in this study. It has been found that female teachers usually have positive attitude towards sex education in school than their male counterparts [19]. This could be the reason for general acceptance of the concepts. Accordingly, several studies in Nigeria had validated the introduction of sex education in schools. In a cross-sectional study carried out in Kwara State, Nigeria, it was gathered that $78 \%$ of the respondents suggested that sex education should be made compulsory in schools [13]. Although, the teaching of strict abstinence from sex encourages self-worth, character building, and skills needed to refuse or accept sexual disposition was well supported by majority of teachers. This teaching however does not acknowledge that many teenagers could become inquisitive about the use of contraceptives, condom especially. It also failed to discuss abortion and sexually transmitted disease [14].

This study revealed that most of the respondents agreed to the teaching of sensitive topics as part of sexual education curriculum. In other study conducted, majority of teachers believed sex education can contribute to the sexual health of the students [15]. However, such teaching may arouse dating desires among students. It may also increase the interest for sexual games, masturbation, inappropriate behaviour which may generate further unhealthy sexual quests. Consequently, the study concluded that respondents posited that sexual education will enhance sexual experimentation and fantasy. Sex education, as encouraged by the teachers, is deeply gendered and this means that sexuality education should be informed by knowledge of gender which was well supported [14].

The result of this study was in support of other work where majority of the respondents asserted that sex education should be included in secondary schools and showed positive attitude toward it [16]. However, it is in variant as majority of the teacher gave the appropriate age to introduce sex education was before 15 years [14] whereas majority of respondents in this study agreed to age between 16 and 18 years. An enormous impact on sensitizing children and young adults before they become sexually active can be made by introducing comprehensive sex education school curriculum delivered by well trained teachers [17].

Also, majority of the respondents agreed to substitute the subject of sex education with more culturally and friendly name. This is identified as one of the difficulties in delivering successful sexuality education, pointing to the fact that many of these teachers had no training. It is a view premised on parental resistance, conservative cultural and religious education and inadequately trained teachers who subtly are uncomfortable with inculcation of the subject into school curriculum [18]. This we perceive will be misleading as students of high schools need sexuality education to enable them make informed decisions about their sexual health and to assist them with developing their sexual identities.

Teachings about physical, emotional and social changes associated with puberty were first among the content of sex education as suggested by respondents in this study. This was closely followed by reproductive tract systems of both male and female. This implies that teachers were not oblivious of bodily changes and the basis for teaching sex education. This is in line with report of importance of sex education in secondary school curriculum where teacher asserted the sex education in the areas of differences in reproductive organs and gender differences will help young ones to establish and accept role and responsibilities of their own gender by acquiring the knowledge of sex [19]. This will help to set up foundation for good awareness about sexuality, interpersonal relationship and hence healthy sexual society.

\section{Conclusion}

This study reflects that most of the respondents agreed to the teaching and inclusion of sex education into school curriculum. The positive attitude and perceptions towards sex educations among teachers of high school is highly 
commendable. This is an indication of the high educational attainments of the teachers. However, their reservations about salient issues about sexuality showed lack of adequate training in human sexuality. Again, culture, conservative religious beliefs and fear in the way of integrating sex education into school curriculum. All hands must be on deck irrespective of the position or stand of teachers to ensure that adolescents receive healthy and factual sex education for allround development at appropriate time, age and class.

\section{References}

[1] United Nations Population Fund (UNFPA) (2010). Operation guidance for comprehensive sexuality education: A focus on Human Rights and Gender pg 5-10.

[2] UNFPA (2010) Comprehensive Sexuality Education; Advancing human Rights, Gender equality and improved sexual and reproductive health: A report of an international consultation to review current evidence and experience, Bogota, Columbia, December.

[3] WHO (2004). Reproductive health strategy to accelerate progress towards the attainment of international development goals and targets. Global strategy adopted by the 57th World Health Assembly. Geneva (http://whqlibdoc.who.int/hq/2004/WHO_RHR_04.8.pdf).

[4] WHO (2006). Defining sexual health. Report of a technical consultation on sexual health, 28-31 January 2002. Geneva.

[5] Collins L (2008). A model middle school sex Education programme (http://economics.txstate.edu/arp/285).

[6] Aransiola J. O, Asa S., Obianjuwa P., Olanrewaju O., Ojo O. O, 5 Fatusi A. O.(2013). Teachers perceptive On Sexual And Reproductive Health Interventions For In-School Adolescents In Nigeria. African Journal of Reproductive Health, December 2013. vol 17(4).

[7] Action Health Inc (2003) Comprehensive Sexuality Education, Trainers resource manual; Lagos; AHI.

[8] Sexuality Information and Education Council of the United Sates (SIECUS) retrieved 7/14/2014.

[9] Meghan Benson (2010). Comprehensive sexuality education. Planned parenthood of Wiscousin inc.
[10] Nwakonobi, F. E \& Onwuachu, W. C (2009). Sex Education; A Way Forward Towards Biology Curriculum Delivery In Secondary Schools In Anambra State. African Research Review. vol 3 (2).

[11] Sanjiv Kumar Bhasin and O. P. Aggarwal (1999). Perceptions of teachers regarding sex education in national capital territory of Delhi. The Indian Journal of Pediatrics 66(4): 527-531.

[12] Lúcia Ramiro, Margarida Gaspar and de Matos (2008) Perceptions of Portuguese teachers about sex education. Revisita Saúde Pública vol.42 no. 4.

[13] Akande AA, Akande T. M. (2007): Knowledge and Perception of Sexuality Education among Students of a rural Secondary School in Kwara state, Nigeria. Nigerian Medical Practitioner vol. 52 No. 3 pp 55-59.

[14] Netsanet Fentahun, Tsion Assefa, 1 Fessahaye Alemseged, and Fentie Ambaw (2012) Parents' Perception, Students' and Teachers' Attitude Towards School Sex Education Ethiopian Journal of Health Science 22(2): 99-106.

[15] Ana Claudia Bortolozzi Maia, Verônica Lima Dos ReisYamauti, Rafaela De Almeida Schiavo, Vera Lúcia Messias Fialho Capellini And Tânia Gracy Martins Do Valle (2015) Teacher opinions on sexuality and Sexual Education of students with intelectual disability Estudos de psicologia (Campinas) vol.32 no.3.

[16] Eko J., Abeshi S., Osonwa K., et am. (2013) Perception of Students, Teachers' and Parents towards sexuality education in Calabar south local government Area of Cross river state, Nigeria. Journal of sociological Research. Vol 4, no 2.

[17] United Nations Educational Scientific and Cultural Organization (UNESCO) (2009). International technical guidance on sexuality education; an evidence-informed approach for schools, teachers and healtheducatorss. Volume 1 .

[18] Mchunu Namisile Joyce (2015) Teachers' perceptions of the teaching of sexuality education in secondary schools in Pinetown district. ResearchSpace.

[19] Nakpodia E. D. (2012). The Relevance Of Sex Education In Secondary School Curricula In Abraka Metropolis, Delta State, Nigeria Scholarly Journal of Business Administration, Vol. 2(2) pp. 36-41. 